\title{
Role of Statins in Coronavirus-Related Disease (COVID-19): A Retrospective Cohort Study in Northern Italy
}

\author{
Salvatore Greco ${ }^{1}$ - Andrea D'Amuri ${ }^{1}$ - Enrico Giorgini ${ }^{1}$ - Francesco Luciani ${ }^{1}$. Mariarosaria Lopreiato ${ }^{1}$. \\ Valeria Fortunato ${ }^{1} \cdot$ Alessandro Scopa $^{1} \cdot$ Grazia Vestita $^{1} \cdot$ Eleonora Capatti $^{2} \cdot$ Angelina Passaro $^{1,2} \mathbb{C}$
}

Received: 2 February 2021 / Accepted: 12 April 2021 / Published online: 27 April 2021

(c) The Author(s) 2021

\begin{abstract}
Introduction The outbreak by SARS-CoV-2 has rapidly spread worldwide. The need for specific treatments to adequately stop the inflammatory response and its sequelae is day by day more urgent and many therapeutic strategies were performed since COVID-19 burst in the last months. Statins were thought to be effective against this novel coronavirus for their antiinflammatory properties, even if the real effects on COVID patients are still partially unexplored.

Methods We retrospectively evaluated 501 adult patients, consecutively admitted to the two COVID-hospitals of Ferrara's territory, and divided them into two groups: ST = patients on statin therapy on admission and NST=patients not on statin therapy on admission. We searched for differences between groups in terms of anamnestic, clinical and laboratory data and then in terms of COVID-19 outcomes.

Results We found significant differences between groups in terms of age, comorbidities, procalcitonin and CPK serum levels: ST patients were older, more comorbid, with lower procalcitonin and higher CPK serum levels. Male sex was, together with the Charlson Comorbidity Index, an independent predictor of needing intensification of care, while age only was a good predictor of in-hospital and 100-day mortality. Differences were also found in the survival functions between the two groups. Conclusions After a period of observation of 100 days, ST patients, despite their older age and their greater load of comorbidities, have similar survival functions to NST patients. If adjusted for age and CCI the survival functions of ST group are considerably more favourable than those of the second group.
\end{abstract}

Keywords COVID-19 $\cdot$ SARS-CoV-2 $\cdot$ Statins $\cdot$ HMG-CoA reductase inhibitor $\cdot$ Survival functions

\section{Introduction}

Coronavirus disease 2019 (COVID-19) is an infectious disease caused by Severe Acute Respiratory Syndrome Coronavirus 2 (SARS-CoV-2) [1] and it is the third coronavirus pandemic of the current century, after SARS (Severe acute respiratory syndrome) and MERS (Middle East respiratory

Salvatore Greco and Andrea D'Amuri equally contributed to the development of this article.

Angelina Passaro

psn@unife.it

1 Department of Translational Medicine, University of Ferrara, Via Luigi Borsari, 46, 44121 Ferrara, Italy

2 Medical Department, University Hospital of Ferrara Arcispedale Sant'Anna, Via Aldo Moro, 8 Cona, 44124 Ferrara, Italy syndrome). The main cause of death is represented by Acute Respiratory Distress Syndrome (ARDS), an immunopathologic event characterized by an uncontrolled systemic inflammatory response and cytokine storm following release of pro-inflammatory cytokines (interferons, interleukins, tumor necrosis factor $\alpha$ and chemokines) [2]. For this reason, recently some researchers proposed or used antiinflammatory agents in the treatment regimen of patients with COVID-19 [3, 4].

Statins are known for their anti-inflammatory effects [5] and some hospitals included them in the COVID-19 treatment protocol [6], even if there is still no clinical evidence that statins are health effective for patients with COVID-19 and there are not much available data about statin therapy in patients with COVID-19.

Among the general major risk factors for developing a severe form of COVID-19 there are diabetes, hypertension and cardiovascular diseases: they are related to higher 
mortality [7], often related to ARDS. On the other hand, conclusive data about the initiation of statins after coronavirus infections are also lacking and there is not an indication to initiate a statin therapy during the acute COVID-19 episodes, excluding clinical trials and conditions where statins therapy is strongly recommended, such as acute myocardial infarction.

About half of all drugs currently available in clinical practice are bio-transformed in the liver primarily by the cytochrome P450 (CYP450) system and the CYP450 system is also responsible for the microsomal metabolism of statins. It can be useful to remember, in the general practice, that some other drugs administered during the first phase of the current pandemic such as macrolide antibiotics and antivirals (e.g. lopinavir, darunavir and their pharmacokinetic enhancers ritonavir and cobicistat) are competitive inhibitors at the enzymatic level, resulting in higher serum levels of statins and thereby in a greater risk of myositis and rhabdomyolysis $[8,9]$ : in such cases, coadministration of statins with these drugs should be avoided, or, in the case of therapy continuation, tight monitoring of transaminases, creatine kinases and renal function markers should be performed. Most statins prescriptions are based on both diabetes and cardiovascular guidelines and it is imperative to underline that there is not any current evidence that the discontinuation of statins during COVID-19 acute episodes can be somehow advantageous.

Lipid-lowering agents are among the best-prescribed drugs in the world. In Italy, in 2018, the consumption of lipid-lowering drugs stood at $92.5 \mathrm{DDD} / 1000$ inhabitants per day (equal to $8 \%$ of consumption by the National Health Service); with "DDD" it is meant the defined daily dose, a statistical measure of drug consumption, defined by the World Health Organization (WHO) Collaborating Centre for Drug Statistics Methodology. About 84\% of the prescription in the category is represented by statins (77.4 DDD).

We decided to perform this retrospective study to assess the real association between statin therapy and the major COVID-19 outcomes. Statin therapy could result, in fact, in a different response in terms of outcomes of hospitalized subjects with SARS-CoV-2 infection.

\section{Methods}

\subsection{Study Design and Data Collection}

This is a retrospective cohort study. It was developed in two hospitals of Ferrara's territory, both dedicated to COVID inpatients during the first SARS-CoV-2 sanitary emergency: "Arcispedale S.Anna" in Cona (Fe), the General and University Hospital of the province and "Ospedale del Delta" in Lagosanto $(\mathrm{Fe})$ were partially set up for receiving patients with the infection.

Between March 15 and June 15, 2020, 501 patients who got a laboratory diagnosis of SARS-CoV-2 infection were consecutively admitted to our two hospitals in the province of Ferrara; the diagnosis was confirmed after the viral RNA detection at the nasopharyngeal swab. We enrolled in the study all patients without any exclusion criterion, collecting their demographic, anamnestic and laboratory data: all data were recorded in an electronic report form and anonymized so that no patient could be identified anymore.

The degree of severity of the population considered was mild or moderate since they were all admitted to our Internal Medicine wards.

For each patient we calculated their Charlson Comorbidity Index (CCI), a validated score useful in clinical practice for better stratification of patients according to their comorbidities [10]; we did the same with MEWS score at admission to our medical departments thinking of a possible role of this score in anticipating a possible worsening of patients' conditions [11]. Inflammation was assessed using white blood count (WBC), C-reactive protein (CRP), procalcitonin and ferritin levels, while organ damage using creatinine, brain natriuretic peptide (BNP), alanine transferase (ALT), isoamylase, creatine phosphokinase (CPK), and troponin I HS (TnI). Length of stay was defined as the duration of stay in an acute hospital setting.

We divided the population into two groups: the first one was made of patients on statin therapy (ST group) before hospital admission, while in the second group (NST group) no one had a clinical reason for being on statin therapy. According to the current guidelines, none of the patients discontinued the statin therapy, nor modified the dosage.

We searched then for differences between groups (ST vs. NST) in terms of demographic, anamnestic, clinical and laboratory data.

We chose as outcomes the following: (1) the need for intensification of care (meant as the admission to the Pulmonology department or the Intensive Care Units-ICUs); (2) the in-hospital mortality; (3) the 100-day mortality. The period of 100 days for the follow-up was arbitrarily chosen in order to obtain a different observation period than that of the in-hospital stay and to ensure a reliable collection of data even in the dismission period after the hospitalization.

The follow-up period of 100 days continued for all the subjects who survived the hospital stay as none of them had a length of stay longer than 100 days. All patients were informed of the potential role of their data in a future study and they signed an informed consent when possible.

We followed STROBE (Strenghtening the Reporting of Observational Studies in Epidemiology) guidelines for reporting observational studies as for the compilation of this manuscript. 
The local Ethics Committee approved the protocol of this study: the protocol code is 521/2020/Oss/AOUFe.

\subsection{Statistical Analysis}

Data analyses were performed by using SPSS 26.0 (IBM SPSS Statistics, IBM Corporation) software. The normal distribution of the continuous variables was analyzed using Kolmogorov-Smirnov and Shapiro-Wilk tests. Variables not normally distributed were log-transformed before entering the parametric statistical analysis. Categorical variables were summarized by using frequencies and percentages, and continuous data were presented as mean \pm standard deviation (SD). The Mann-Whitney U test was used for continuous variables, and the $\chi^{2}$ test or the Fisher exact test was used for categorical variables. Variables with a $p$ value $<0.05$ in the univariate analyses were entered into multivariate logistic regression analyses. The Cox regression analyses were performed for evaluating the survival functions of both the groups of patients on statin therapy and not on statin therapy. All $p$ values $<0.05$ are considered statistically significant.

\section{Results}

Between March 15 and June 15, 2020, a total of 501 patients were hospitalized with a laboratory diagnosis of SARS-CoV-2 infection in the two main hospitals of Ferrara's territory ("Arcispedale S.Anna" in Cona and "Ospedale del Delta" in Lagosanto), both partially dedicated to COVID inpatients.

51 subjects upon the total of $501(10.2 \%)$ had statins in their home therapy, while the remaining 450 did not; 35 patients were taking atorvastatin $(68.6 \%), 14$ simvastatin (27.5\%) and only 2 pravastatin (3.9\%). 10 patients upon the 35 taking atorvastatin $(28.6 \%)$, were on high-intensity statin therapy, meant as a dosage of at least $40 \mathrm{mg} /$ daily of atorvastatin.
Table 1 Demographic, clinical and laboratory data of patients (ST=on statin therapy vs. NST $=$ not on statin therapy)

\begin{tabular}{llllll}
\hline $\mathrm{N}=501$ & Total cohort & Min-Max & ST $(\mathrm{n}=51)$ & NST $(\mathrm{n}=450)$ & $\mathrm{p}$ value \\
\hline Age, years & $72 \pm 17$ & $19-99$ & $76 \pm 10$ & $71 \pm 17$ & $\mathbf{0 . 0 3 0}$ \\
CCI, points & $2.0 \pm 2.3$ & $0-12$ & $2.8 \pm 2.4$ & $2.0 \pm 1.3$ & $\mathbf{0 . 0 1 0}$ \\
Length of stay, days & $19 \pm 15$ & $1-92$ & $16 \pm 11$ & $20 \pm 15$ & 0.120 \\
MEWS score, points & $1.8 \pm 1.2$ & $0-9$ & $1.7 \pm 0.96$ & $1.8 \pm 1.2$ & 0.520 \\
SBP, mmHg & $129 \pm 21$ & $80-190$ & $135 \pm 23$ & $129 \pm 21$ & $\mathbf{0 . 0 5 0}$ \\
DBP, mmHg & $74 \pm 12$ & $40-120$ & $74 \pm 12$ & $73 \pm 12$ & 0.650 \\
HR, bpm & $85 \pm 17$ & $43-159$ & $83 \pm 15$ & $86 \pm 17$ & 0.270 \\
RR, apm & $22 \pm 6$ & $12-59$ & $22 \pm 7$ & $22 \pm 6$ & 0.880 \\
P/F ratio & $284 \pm 111$ & $68-971$ & $288 \pm 93$ & $284 \pm 113$ & 0.850 \\
WBC, n/mmc & $8354 \pm 6838$ & $1720-101,730$ & $6865 \pm 2705$ & $8524 \pm 7143$ & 0.310 \\
Lymphocytes, n/mmc & $1340 \pm 2647$ & $129-46,540$ & $1041 \pm 501$ & $1374 \pm 2787$ & 0.330 \\
CRP, mg/dl & $8.3 \pm 8.6$ & $0-65$ & $6.4 \pm 5.6$ & $8.5 \pm 8.9$ & 0.110 \\
Procalcitonin, (ng/ml) & $1.6 \pm 6.9$ & $0-100$ & $0.9 \pm 2.8$ & $1.7 \pm 7.4$ & $\mathbf{0 . 0 1 0}$ \\
Creatinine, mg/dl & $1.37 \pm 1.66$ & $0.1-19.6$ & $1.14 \pm 0.60$ & $1.4 \pm 1.7$ & 0.760 \\
eGFR, ml/min & $67 \pm 31$ & $0.5-173.6$ & $64 \pm 23$ & $67 \pm 32$ & 0.520 \\
LDH, mg/dl & $305 \pm 164$ & $59-1741$ & $301 \pm 98$ & $305 \pm 171$ & 0.280 \\
BNP, pg/ml & $244 \pm 528$ & $0-5000$ & $181 \pm 198$ & $255 \pm 566$ & 0.370 \\
Fibrinogen, mg/dl & $536 \pm 182$ & $113-1277$ & $534 \pm 173$ & $536 \pm 183$ & 0.950 \\
D-Dimer, ng/ml & $2.6 \pm 5.1$ & $0-35$ & $2.5 \pm 5.0$ & $2.6 \pm 5.2$ & 0.860 \\
Isoamylase, U/l & $47 \pm 52$ & $1-571$ & $38 \pm 40$ & $48 \pm 54$ & 0.330 \\
ALT, U/l & $36 \pm 68$ & $3-1120$ & $24 \pm 15$ & $38 \pm 72$ & 0.300 \\
CPK, U/l & $283 \pm 1124$ & $10-16,333$ & $336 \pm 463$ & $275 \pm 1191$ & $\mathbf{0 . 0 0 3}$ \\
Ferritin, ng/ml & $618-877$ & $5-6399$ & $711 \pm 1361$ & $608 \pm 807$ & 0.890 \\
Troponin, ng/ml & $70 \pm 293$ & $0-3704$ & $84 \pm 248$ & $68 \pm 302$ & 0.060 \\
\hline & & & & \\
\hline
\end{tabular}

All data are expressed as mean \pm SD

Bold $\mathrm{p}$ values $<0.05$ are considered statistically significant

$C C I$ Charlson Comorbidity Index, MEWS Modified Early Warning Score, SBP Sistolic blood pressure, $D B P$ diastolic blood pressure, $H R$ heart rate, $R R$ respiratory rate, $W B C$ white blood cells, $C R P C$ reactive protein, $e G F R$ estimated Glomerular filtration rate, $L D H$ lactic dehydrogenase, $B N P$ brain natriuretic peptide, $A L T$ alanine transferase, $C P K$ creatinine phosphokinase 
The whole population was also divided into two groups (ST vs. NST) as shown in Table 1. Patients on statin therapy were on average older than patients who did not take statins before being admitted to hospital ( $76 \pm 10$ vs. $71 \pm 17$ years, $p=0.03$ ), had a greater Charlson Comorbidity Index $(2.8 \pm 2.4$ vs. $2.0 \pm 1.3$ points; $p=0.01)$ and higher systolic blood pressure ( $135 \pm 23$ vs. $129 \pm 21$ $\mathrm{mmHg} ; p=0.05$ )

As expected, they also had higher CPK serum levels than patients did without statin therapy $(336 \pm 463$ vs. $275 \pm 1191 \mathrm{U} / \mathrm{L} ; p=0.003$ ). Significant differences were also found for procalcitonin levels: ST patients had lower serum levels of procalcitonin than NST patients $(0.9 \pm 2.8$ vs. $1.7 \pm 7.4 \mathrm{ng} / \mathrm{ml} ; p=0.01$ ).

In Table 2 we recapitulated the percentage of comorbidities by patients of the two groups: patients on statin therapy had more frequently hypertension $(80.4 \%$ vs. $59.4 \%$, $p=0.003)$, a history of hematological or localized cancer

Table 2 Comorbidities on admission (ST = on statin therapy vs. NST $=$ not on statin therapy).

\begin{tabular}{lccr}
\hline N = 501 & ST (N=51) & NST (N =450) & p value \\
\hline Men, N.(\%) & $27(52.9)$ & $227(50.3)$ & 0.740 \\
Women, N.(\%) & $24(47.1)$ & $224(49.7)$ & \\
Smoking habit, N.(\%) & $15(29.4)$ & $74(16.4)$ & $\mathbf{0 . 0 3 0}$ \\
Hypertension, N.(\%) & $41(80.4)$ & $268(59.4)$ & $\mathbf{0 . 0 3 0}$ \\
Diabetes, N.(\%) & $22(43.1)$ & $43(9.5)$ & $<\mathbf{0 . 0 0 1}$ \\
Heart failure, N.(\%) & $6(11.8)$ & $50(11.1)$ & 0.870 \\
CKD (III-IV-V stage), & $7(13.7)$ & $58(12.9)$ & 0.860 \\
$\quad$ N.(\%) & $9(17.6)$ & $59(13.1)$ & 0.360 \\
Stroke or TIA, N.(\%) & $4(7.8)$ & $24(5.3)$ & 0.460 \\
PCOA, N.(\%) & $4(7.8)$ & $441(9.1)$ & 0.770 \\
COPD, N.(\%) & $71(15.7)$ & $\mathbf{0 . 0 3 0}$ \\
Localized or hematological & $14(27.5)$ & & \\
$\quad$ cancer, N.(\%) & & $25(5.5)$ & 0.630 \\
Metastatic cancer, N.(\%) & $2(3.9)$ & $117(26.0)$ & 0.730 \\
Dementia, N.(\%) & $12(23.5)$ & \\
\hline
\end{tabular}

Bold $\mathrm{p}$ values $<0.05$ are considered statistically significant

$C K D$ chronic kidney disease, TIA transient ischemic attack, PCOA peripheral chronic obstructive arteriopathy, $C O P D$ chronic obstructive pulmonary disease
( $27.5 \%$ vs. $15.7 \%, p=0.03)$, diabetes $(43.1 \%$ vs. $9.5 \%, p$ $<0.001)$ and smoking habit $(29.4 \%$ vs. $16.4 \%, p=0.03)$.

We further analyzed the population trying to check whether ST patients underwent different outcomes compared to NST patients. Table 3 shows no significant differences between groups in terms of the need for intensification of care in, in-hospital mortality and 100-day mortality: 16 ST subjects upon 51 (30.4\%) underwent intensification of care vs. 113 subjects upon 450 of the NST population (25.1\%); 11 ST subjects upon $51(21.6 \%)$ vs. 117 NST subjects upon $450(26.0 \%)$ died within the in-hospital period, while as for the last outcome chosen, 15 ST patients upon 51 (29.4\%) vs. 140 subjects upon 450 (31.1\%) died within the observation period of 100 days.

Specific analyses were performed for the group of ST patients considering that, during the hospitalization, some of them were treated also with CYP450 inducers such as macrolides (azithromycin only) and antivirals (lopinavir, darunavir and their pharmacokinetic enhancers ritonavir and cobicistat). These analyses showed that the only slightly significant correlation concerned the two sub-groups of patients who received or not the antiviral therapy; in particular, those who did not receive such therapy appeared to undergo less often an intensification of care $(46.2 \%$ vs. $76.3 \%, p=0.04)$.

Table 4 Logistic regression analyses of intensification of care.

\begin{tabular}{lccc}
\hline Variables & OR & $95 \%$ CI & p value \\
\hline Age & 1.00 & $0.98-1.02$ & 0.87 \\
Sex (M) & 2.91 & $1.74-4.85$ & $<\mathbf{0 . 0 0 1}$ \\
CCI & 0.83 & $0.71-0.97$ & $\mathbf{0 . 0 2}$ \\
Statin therapy & 1.00 & $0.47-2.14$ & 0.99 \\
Hypertension & 1.72 & $0.95-3.11$ & 0.08 \\
Diabetes & 1.05 & $0.51-2.18$ & 0.89 \\
Coronary artery disease & 1.09 & $0.50-2.62$ & 0.86 \\
COPD & 1.16 & $0.44-3.11$ & 0.77 \\
\hline
\end{tabular}

Categorical parameters in relation to the need for intensification of care

Bold $\mathrm{p}$ values $<0.05$ are considered statistically significant

OR odds ratio, 95\% CI 95\% Confidential Interval, CCI Charlson Comorbidity Index, $C O P D$ chronic obstructive pulmonary disease

Table 3 Univariate analyses of COVID-19 outcomes.

\begin{tabular}{|c|c|c|c|c|c|c|c|c|c|}
\hline \multirow[t]{2}{*}{$\mathrm{N}=501$} & \multicolumn{2}{|c|}{ Intensification of care n.(\%) } & \multirow[t]{2}{*}{$\mathrm{p}$ value } & \multicolumn{2}{|c|}{ In-hospital death n.(\%) } & \multirow[t]{2}{*}{$\mathrm{p}$ value } & \multicolumn{2}{|c|}{ 100-day mortality } & \multirow[t]{2}{*}{$\mathrm{p}$ value } \\
\hline & Yes & No & & Yes & No & & Yes & No & \\
\hline $\mathrm{ST}(\mathrm{n}=51)$ & $16(30.4)$ & $35(69.6)$ & 0.33 & $11(21.6)$ & $40(78.4)$ & 0.49 & $15(29.4)$ & $36(70.6)$ & 0.81 \\
\hline $\operatorname{NST}(n=450)$ & $113(25.1)$ & $337(74.9)$ & & $117(26.0)$ & $333(74.0)$ & & $140(31.1)$ & $311(68.9)$ & \\
\hline
\end{tabular}

Comparison between groups ( $\mathrm{ST}=$ on statin therapy vs. NST $=$ not on statin therapy) in terms of intensification of care, in-hospital death, and 100-day mortality 
Table 5 Logistic regression analyses of in-hospital mortality.

\begin{tabular}{lllc}
\hline Variables & OR & $95 \%$ CI & p value \\
\hline Age & 1.08 & $1.05-1.11$ & $<\mathbf{0 . 0 0 1}$ \\
Sex $(M)$ & 1.35 & $0.76-2.42$ & 0.31 \\
CCI & 1.08 & $0.94-1.23$ & 0.29 \\
Statin therapy & 0.45 & $0.19-1.04$ & 0.06 \\
Hypertension & 0.84 & $0.44-1.62$ & 0.61 \\
Diabetes & 1.58 & $0.77-3.25$ & 0.21 \\
Coronary artery disease & 1.93 & $0.85-4.36$ & 0.12 \\
COPD & 1.21 & $0.47-3.12$ & 0.69 \\
\hline
\end{tabular}

Categorical parameters in relation to death within the hospitalization period

Bold $\mathrm{p}$ value $<0.05$ is considered statistically significant

OR odds ratio, 95\% CI 95\% confidential interval, CCI Charlson Comorbidity Index, $C O P D$ chronic obstructive pulmonary disease

Table 6 Logistic regression analyses of 100-day survival.

\begin{tabular}{lccc}
\hline Variables & OR & $95 \%$ CI & p value \\
\hline Age & 1.08 & $1.05-1.11$ & $<\mathbf{0 . 0 0 1}$ \\
Sex $(M)$ & 1.04 & $0.60-1.79$ & 0.90 \\
CCI & 1.12 & $0.98-1.27$ & 0.10 \\
Statin therapy & 0.63 & $0.29-1.35$ & 0.23 \\
Hypertension & 0.87 & $0.47-1.61$ & 0.65 \\
Diabetes & 1.08 & $0.54-2.19$ & 0.83 \\
Coronary artery disease & 1.36 & $0.61-3.04$ & 0.46 \\
COPD & 1.30 & $0.53-3.20$ & 0.57 \\
\hline
\end{tabular}

Categorical parameters in relation to death after 100 days

Bold $\mathrm{p}$ value $<0.05$ is considered statistically significant

OR odds ratio, 95\% CI 95\% confidential interval, CCI Charlson Comorbidity Index, $C O P D$ chronic obstructive pulmonary disease

The analyses concerning the CYP450 inducers can be found in the Supplementary table.

Multivariate analyses were performed to confirm that, limitedly to our cohort of patients, statin therapy did not clearly modify the COVID-19 short-term outcomes, at least if considered with such statistical analyses. Table 4 shows that the two variables strongly associated with the need for intensification of care were sex (OR 2.91, 95\% CI $1.74-4.85, p<0.001)$ and the Charlson Comorbidity Index (OR 0.83, 95\% CI 0.71-0.97, $p=0.02$ ).

As for mortality (in-hospital and at the 100th day since hospital admission), the only determining variable was age (OR $1.08,95 \%$ CI $1.05-1.11, p<0.001$ for both mortality rates). These data are shown in Tables 5 and 6.

To understand the role of the variables age and CCI, supposing them to be the two main selection bias of our findings, we decided to perform two separate Cox

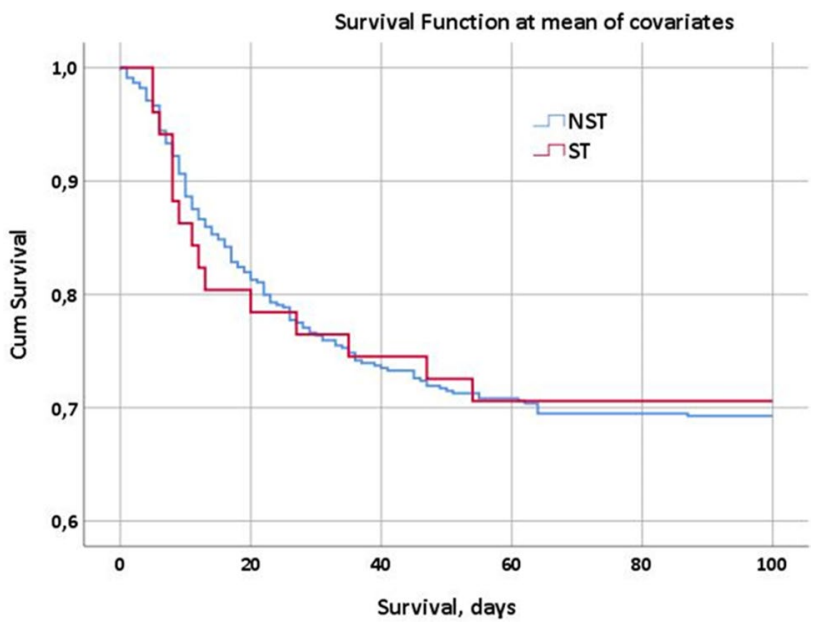

Fig. 1 Cox regression analysis, survival at the 100th day since the first positive viral RNA detection in both populations of patients (on statin therapy, ST $=$ red curve vs. not on statin therapy, NST=blue curve)

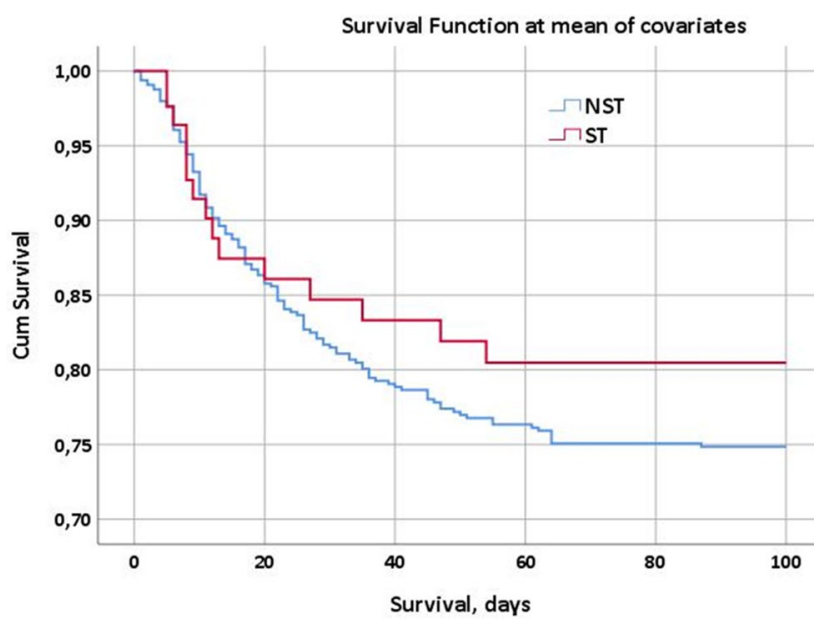

Fig. 2 Cox regression analysis, survival at the 100th day since the first positive viral RNA detection in both populations of patients (on statin therapy, ST =red curve vs. not on statin therapy, NST=blue curve) adjusted for age and CCI (Charlson Comorbidity Index). The red curve intercepts the blue curve in its first descending tract, but they take different directions after a longer observation time, resulting in two different survival functions

regression analyses, that determined the survival curves of the population on statin therapy (ST) and not on statin therapy (NST). The Cox regression analysis in Fig. 1 shows the survival curves of both populations after 100 days of observation without any adjustment. In Fig. 2 it is shown the Cox regression analysis for the same populations of patients but with the adjustment for age and 
comorbidities (weighted through the CCI): the population of patients on statin therapy seems to survive longer if compared to that of patients not on statin therapy $(p<0.001)$.

\section{Discussion}

In this study, we evaluated the effects of statin therapy on COVID-19 outcomes. The prevalence of inpatients with SARS-CoV-2 infection, who were already on statin therapy at hospital entry in Ferrara's province, was 10.2\% (51 subjects upon 501).

First of all, we divided the population into two groups, distinguished on the basis of their home drug therapy: patients who were already taking statins before being admitted to our hospitals with a diagnosis of SARS-CoV-2 infection were assigned to the first group (ST), while patients without statin therapy at home were allocated in the second group (NST). We investigated the differences between groups in terms of demographic, clinical and laboratory data, finding significant results for age, Charlson Comorbidity Index (CCI), systolic blood pressure, procalcitonin and CPK serum levels.

ST patients were on average older than those of the NST group (76 \pm 10 vs. $71 \pm 17$ years) and they had a greater CCI ( $2.8 \pm 2.4$ vs. $2.0 \pm 2.3$ points $)$, thus resulting to have more comorbidities. The first consideration is about age: it is no surprise that ST patients are older than NST patients, and the same can be said for their different Charlson Comorbidity Indexes. Statins are, in fact, often prescribed to older and more comorbid patients due to their positive effects in reducing significantly the number of major vascular events, irrespective of age, even if there is less definitive direct evidence of benefit in the primary prevention setting among patients older than 75 years. Anyway, evidence supports the use of statin therapy in older people considered to have a sufficiently high risk of occlusive vascular events [12].

In our cohort, patients on statin therapy had also higher mean systolic blood pressure and CPK serum levels, while procalcitonin serum levels were significantly lower compared with patients of the other group.

As for the higher levels of systolic blood pressure registered in the group of ST patients, the explanation can be found in the higher percentage of patients treated for hypertension in this group if compared to the group of NST patients $(80.4 \%$ vs. $59.4 \%)$. Equally easy to explain is the difference between groups in terms of serum levels of creatine phosphokinase (CPK): CPK elevation, with or without myopathy, is strictly associated with statin therapy and it could be considered as one of the most known side effects of such drug therapy [13].
Certainly, more complicated to explain is the relationship between statins and procalcitonin; in this study, the two groups were significantly different in terms of procalcitonin serum levels, with lower serum levels of procalcitonin in the ST population $(0.9 \pm 2.8$ vs. $1.7 \pm 7.4 \mathrm{ng} / \mathrm{ml})$. Several studies in the last years have reported improved survivals in severe bacterial infections among statin-treated patients and one of the proposed mechanisms at the base of this phenomenon is the anti-inflammatory effect of statins, as explained above. A systematic review by Kopterides et al. [14], in 2009 , investigated the role of statins in infections, showing how the statin treatment is generally associated with a better prognosis in severe bacterial diseases. In 2010, BjörkhemBergman et al., in their meta-analysis [15], recapitulated the effects of statins in bacterial infections, showing a strong association with a better prognosis. However, the adjustments made for apparent publication bias, modified the results of the analyses and the associations observed did not reach statistical significance anymore.

We decided to investigate the differences between the two main groups of patients also in terms of disease outcomes (1, The need for intensification of care; 2, in-hospital mortality; 3, 100-day mortality), finding no significant differences for any of the evaluated variables. Multivariate analyses were also performed to check whether there were variables that could somehow predict the COVID-19 outcomes. We chose age, sex, CCI and statin therapy as variables of the analysis, considering then also some of the most known negative prognostic factors such as hypertension, diabetes, coronary artery disease and COPD. We found the male sex to be an independent risk factor for undergoing the intensification of care (OR 2.91) together with CCI and age for the in-hospital and the 100-day mortality.

The univariate analyses did not show any significant associations between the statin therapy and the three COVID-19 outcomes chosen, while the multivariate analyses performed showed strong relationships between sex and the need for intensification of care. In particular, men underwent intensification of care with much more probability than women as already observed in other studies [16, 17]. The Charlson Comorbidity Index was also strongly associated with the need for intensification of care (OR 0.83).

Behind this difference between men and women, there is not certainly any kind of sex discrimination, but probably the key to reading this data is the different age of men and women in both groups. As for the ST group, there were 27 men and 24 women and there was not a significant difference between their mean ages $(75 \pm 11$ vs. $78 \pm 8$ years; $p=0.27$ ), while in the group of NST patients there were 227 men and 223 women and there was a substantial difference in terms of mean age ( $68 \pm 16$ vs. $74 \pm 18$ years, $p<0.001$ ). If we calculate the differences between men and women for age in the whole population, we notice how 
women are on average substantially older than men $(69 \pm 16$ vs. $75 \pm 17$ years, $p<0.001$ ), even if there were no significant sex-related differences in terms of comorbidities: the mean Charlson comorbidity indexes are, in fact, not different between men and women $(2.0 \pm 2.3$ vs. $2.1 \pm 2.3$ points; $p=0.46$ ). statistical analyses concerning the age and the comorbidity indexes of patients divided by sex are not shown in the tables below. Women, in short, were older than men and we can state that this was the main reason why men were more often candidate for the intensification of care. Similarly, as CCI showed a "protective" role in determining the need for intensification of care, we could say that the clinicians' choice towards more intensive care settings was based also on the charge of comorbidities of the patient. The eligibility of patients to the intensification of care needs to be established according to the estimated probability of overcoming the disease: scoring systems may guide clinicians through it but clinical judgment remains the core skill when dealing with end-of-life events and decisions [18]. Age and comorbidities are always to be taken into consideration before making patients eligible for admission to ICUs or to Pulmonology departments and both can help estimate the chances of success towards the intensification of care.

The analyses concerning the drugs acting on CYP450, shown in the Supplementary table, indicated that the patients who did not receive such therapy appeared to undergo less often an intensification of care $(p=0.04)$. However, in this case, the small size of the sample considered does not allow to get to any conclusion and many variables could have influenced this finding, such as the timing of the administration since the first symptoms or the age of the patients that were not considered in the eligibility of the patients themselves to the antiviral therapy.

As for the in-hospital and the 100-day mortality rates, the multivariate analyses summarized in Tables 5 and 6 showed that the only variable independently associated with both mortality rates was age (OR 1.08; 95\% CI 1.05-1.11, $p<0.001$ for the in-hospital and the 100-day mortality rate).

This point is easily interpretable and it is not surprising that the elderly patients are those at higher risk of death during the hospital stay or after a short period (in this case it was considered a 100-day period) since hospital admission.

The results of the Cox regression analyses registered in Figs. 1 and 2 are surely more interesting and worthy of further consideration. Figure 1 figures the survival function of both the populations on statin therapy and not on statin therapy, showing no substantial differences at the observation after 100 days since hospital admission. The same analysis, adjusted for age and CCI represented in Fig. 2, shows different trends in the 100-day mortality between the ST and NST populations: after the first days of observation, in fact, the two curves show evident differences in terms of survival at the 100th day since hospital admission: the red curve, representing the ST population, shows better survival function than the blue curve that represents, instead, the NST population. These data are in line with those previously observed in some other studies concerning COVID inpatients on statin therapy: recently, Zhang et al. [19] reported that, on a total of 13,981 recruited in their study, whose 1219 were on statin therapy, the death rate of statin users and nonusers were respectively $5.2 \%$ and $9.4 \%$ Moreover, a recent meta-analysis by Kow et al. [20] including a total of 8990 COVID patients from 4 different studies revealed a significantly reduced hazard ratio for fatal or severe disease with the use of statins (HR 0.70; 95\% CI 0.53-0.94). Another metaanalysis by Onorato et al. [21] on a total of 170 studies about statins in COVID-19 suggested a potential beneficial effect of statins in patients with COVID-19, especially when these drugs were initiated before hospital admission. Similarly, a study by Gupta et al. [22] on 2626 patients found that the antecedent statin use in patients hospitalized with COVID-19 is associated with lower inpatient mortality (OR 0.47).

The "meeting point" between the different theories underlying the anti-inflammatory effect of statins seems to be the immunomodulatory effect of statins on the TLR-MyD88 pathway. In 2015, some researchers from the USA demonstrated that the Toll-like receptor 3 signaling (TLR3 is a member of the sensor proteins Toll-like receptors) contributes to a protective innate immune response to severe acute respiratory syndrome coronavirus (SARS-CoV) infection. Gene expression of myeloid differentiation primary response 88 (MyD88) is induced by SARS-CoV infection and its product acts downstream of TLRs [23]. Both over-expression and under-expression of MyD88 gene were related to increased mortality after MERS-CoV infection [24]. NF-kB is activated by coronavirus infections, downstream of TLRsMyD88 pathways. Mice models showed how the inhibition of NF-kB improved lung affection and survival after SARSCoV infection [25].

Some animal studies showed that an excessive inhibition of TLR adaptor TRIF or MyD88 signaling, results in severe lung damage and death, probably due to the activation of different compensatory immunologic pathways. Further animal studies also showed that with abolished TLR pathways the viral load and risk of coronavirus transmission to other humans were higher [26].

Among TLR-MyD88 antagonists, statins are probably the most common FDA-approved drugs and they do not affect the MyD88 level significantly under normal conditions, while they preserve MyD88 at a normal level during hypoxia mitigating NF-kB activation [27]. For this reason, some researchers hypothesized it to be helpful to use statins in the case of MERS-CoV [28] and SARS-CoV-2 infections [29]. 
Statins, by the potential to inhibit TLR pathways and NF-kB response, carry the potential risk of exacerbating such compensatory immune factors resulting in poor disease outcomes. Some human and animal studies have shown lung injury improvements due to the anti-inflammatory effects of statins $[30,31]$ while a retrospective analysis of a multicenter clinical trial on the efficacy of rosuvastatin against infection-induced ARDS showed higher IL-18 levels and mortality in statin-treated patients [32]. Equally conflicting are the findings on the effects of statins in patients with community-acquired [33] and ventilator-associated pneumonia [34-36].

This cohort study underlines the role of statin therapy in modifying the COVID-19 outcomes. In particular, as shown above, the patients who were already on statin therapy on hospital admission had a lower 100-day mortality rate when compared to the patients who did not have statins in their home therapy. This difference is particularly evident in adjusting the data for age and comorbidities, in order to eliminate the two main selection biases of the analyses, and can find a possible explanation in the anti-inflammatory effect of statins even in the SARS-CoV-2 infection.

What is important to underline is that statins are safe drugs in general and all the studies agree in stating that they are not only safe to be administered during SARSCoV-2 infection, but they can also improve COVID-19 outcomes, especially when longer periods of observation are considered.

Certainly, this study is not free from limitations and these are related to its retrospective nature and to the restricted sample size, which could have limited the significance of our findings. Furthermore, the study population included only hospitalized subjects, so extrapolation of the conclusions to the general population with SARS-CoV-2 infection requires caution. Lastly, the observation time is limited to 100 days for each patient and it did not consider longer follow-up periods so that it is not possible to dissert about the long-term consequences on the COVID-19 outcomes by the statin therapy.

For all these reasons it is still necessary to better investigate and deepen the relationships between statin therapy and viral infections such as SARS-CoV-2 infection; as always, randomized-controlled trials concerning the efficacy of statins against COVID-19 are needed for confirmation or refutation of such findings.

\section{Conclusions}

This study was aimed at evaluating the possible effects of statins on COVID-19 outcomes. The positive consequences of a lipid profile improvement are well known in patients with cardiovascular diseases and in general in those with a high risk of developing major cardiovascular events, but it is not yet clear what the effects of statin therapy are in patients with SARS-CoV-2 infection.

Our study showed some interesting data about the different mortality rates of patients with and without statin therapy on admission to our two hospitals. In particular, after a period of observation of 100 days, patients on statin therapy, despite their older age and their greater load of comorbidities, have similar survival functions to those of patients in the cohort not on statin therapy. Moreover, if adjusted for age and Charlson Comorbidity Index (CCI) the survival functions of patients on statin therapy are considerably more favourable than those of patients not taking statins on hospital admission.

Supplementary Information The online version contains supplementary material available at https://doi.org/10.1007/s40292-021-00452-y.

Acknowledgements No funding was provided to support the preparation of this article. We would like to dedicate our sincere thanks to all the members of the medical staff that is still participating in the fight against this pandemic, to all the extremely skillful and valuable nursing staff members as well as our assistance personnel, every day working on the frontline. Special thanks to the directors of the Internal Medicine Units where our research took place: Giovanni Zuliani MD, $\mathrm{PhD}$, director of the "University Internal Medicine" department of "Arcispedale S.Anna" in Cona (Fe), Roberto Manfredini MD, PhD, director of the "Clinical Medicine" department of "Arcispedale S.Anna" in Cona (Fe) and Stefano Parini, MD, director of the "Internal Medicine" department of "Ospedale del Delta" in Lagosanto (Fe).

Author contribution GS: acquisition, analysis and interpretation of data; drafting the article. DA: acquisition, analysis and interpretation of data; drafting the article. LF: acquisition, analysis and interpretation of data; drafting the article. GE: acquisition, analysis and interpretation of data; drafting the article. LM: acquisition and analysis of data. FV: acquisition and analysis of data. VG: acquisition and analysis of data. $\mathrm{CE}$ : revising the article critically for important intellectual content. PA: the conception and design of the study; drafting the article and revising it critically for important intellectual content, final approval of the version to be submitted.

Funding Open access funding provided by Università degli Studi di Ferrara within the CRUI-CARE Agreement.

\section{Declarations}

Conflict of interest On behalf of all authors, the corresponding author states that there is no conflict of interest. The authors declare that they have no known competing financial interests or personal relationships that could have appeared to influence the work reported in this paper.

Open Access This article is licensed under a Creative Commons Attribution-NonCommercial 4.0 International License, which permits any non-commercial use, sharing, adaptation, distribution and reproduction in any medium or format, as long as you give appropriate credit to the original author(s) and the source, provide a link to the Creative Commons licence, and indicate if changes were made. The images or other third party material in this article are included in the article's Creative 
Commons licence, unless indicated otherwise in a credit line to the material. If material is not included in the article's Creative Commons licence and your intended use is not permitted by statutory regulation or exceeds the permitted use, you will need to obtain permission directly from the copyright holder. To view a copy of this licence, visit http://creativecommons.org/licenses/by-nc/4.0/.

\section{References}

1. Stawicki S, Jeanmonod R, Miller A, Paladino L, Gaieski D, Yaffee A, De Wulf A, Grover J, Papadimos T, Bloem C, Galwankar S, Chauhan V, Firstenberg M, Di-Somma S, Jeanmonod D, Garg S, Tucci V, Anderson H, Fatimah L, Worlton T, Dubhashi S, Glaze K, Sinha S, Opara I, Yellapu V, Kelkar D, El-Menyar A, Krishnan V, Venkataramanaiah S, Leyfman Y, Saoud-Al-Thani H, Nanayakkara PB, Nanda S, Cioè-Peña E, Sardesai I, Chandra S, Munasinghe A, Dutta V, Dal-Ponte S, Izurieta R, Asensio J, Garg M. The 2019-2020 novel coronavirus (severe acute respiratory syndrome coronavirus 2) pandemic: A joint american college of academic international medicine-world academic council of emergency medicine multidisciplinary COVID-19 working group consensus paper. J Glob Infect Dis. 2020;12:47. https://doi.org/10.4103/jgid. jgid_86_20.

2. Guan W, Ni Z, Hu Y, Liang W-H, Ou C, He J, Liu L, Shan H, Lei C, Hui DSC, Du B, Li L-J, Zeng G, Yuen K-Y, Chen R-C, Tang C, Wang T, Chen P-Y, Xiang J, Li S-Y, Wang J-L, Liang Z, Peng Y-X, Wei L, Liu Y, Hu Y, Peng P, Wang J, Liu J, Chen Z, Li G, Zheng Z, Qiu S, Luo J, Ye C, Zhu S, Zhong N. China medical treatment expert group for Covid-19, clinical characteristics of coronavirus disease 2019 in China. N Engl J Med. 2020;382:1708-20. https://doi.org/10.1056/NEJMoa2002032.

3. Conti P, Ronconi G, Caraffa A, Gallenga C, Ross R, Frydas I, Kritas S. Induction of pro-inflammatory cytokines (IL-1 and IL-6) and lung inflammation by Coronavirus-19 (COVI-19 or SARSCoV-2): anti-inflammatory strategies. J Biol Regul Homeost Agents. 2020;34:327-31. https://doi.org/10.23812/CONTI-E.

4. Zhang W, Zhao Y, Zhang F, Wang Q, Li T, Liu Z, Wang J, Qin Y, Zhang X, Yan X, Zeng X, Zhang S. The use of anti-inflammatory drugs in the treatment of people with severe coronavirus disease 2019 (COVID-19): the perspectives of clinical immunologists from China. Clin Immunol. 2020;214:108393. https://doi.org/10. 1016/j.clim.2020.108393.

5. Schonbeck U. Inflammation, immunity, and HMG-CoA reductase inhibitors: statins as antiinflammatory agents? Circulation. 2004;109:II-18-II-26. https://doi.org/10.1161/01.CIR.00001 29505.34151.23

6. Ginsberg LE. Massachusetts general hospital COVID-19 treatment guidance, Massachusetts Gen. Hosp. 2020. https://www. massgeneral.org/assets/MGH/pdf/news/coronavirus/mass-gener al-COVID-19-treatment-guidance.pdf

7. Wu C, Chen X, Cai Y, Xia J, Zhou X, Xu S, Huang H, Zhang L, Zhou X, Du C, Zhang Y, Song J, Wang S, Chao Y, Yang Z, Xu J, Zhou X, Chen D, Xiong W, Xu L, Zhou F, Jiang J, Bai C, Zheng J, Song Y. Risk factors associated with acute respiratory distress syndrome and death in patients with coronavirus disease 2019 pneumonia in Wuhan, China. JAMA Intern Med. 2020;180:934. https://doi.org/10.1001/jamainternmed.2020.0994.

8. Pasternak RC, Smith SC, Bairey-Merz CN, Grundy SM, Cleeman JI, Lenfant C. ACC/AHA/NHLBI clinical advisory on the use and safety of statins. Circulation. 2002;106:1024-8. https://doi.org/10. 1161/01.CIR.0000032466.44170.44.
9. Bellosta S, Paoletti R, Corsini A. Safety of statins: focus on clinical pharmacokinetics and drug interactions. Circulation. 2004;109:50-7. https://doi.org/10.1161/01.CIR.0000131519. 15067.1f.

10. Charlson ME, Pompei P, Ales KL, MacKenzie CR. A new method of classifying prognostic comorbidity in longitudinal studies: development and validation. J Chronic Dis. 1987;40:373-83. https://doi.org/10.1016/0021-9681(87)90171-8.

11. Subbe CP, Kruger M, Rutherford P, Gemmel L. Validation of a modified early warning score in medical admissions. QJM. 2001;94:521-6. https://doi.org/10.1093/qjmed/94.10.521.

12. Armitage J, Baigent C, Barnes E, Betteridge DJ, Blackwell L, Blazing M, Bowman L, Braunwald E, Byington R, Cannon C, Clearfield M, Colhoun H, Collins R, Dahlöf B, Davies K, Davis B, de Lemos J, Downs JR, Durrington P, Emberson J, Fellström B, Flather M, Ford I, Franzosi MG, Fulcher J, Fuller J, Furberg C, Gordon D, Goto S, Gotto A, Halls H, Harper C, Hawkins CM, Herrington W, Hitman G, Holdaas H, Holland L, Jardine A, Jukema JW, Kastelein J, Kean S, Keech A, Kirby A, Kjekshus J, Knatterud G, Knopp R, Koenig W, Koren M, Krane V, Landray MJ, LaRosa J, Lonn E, MacFarlane P, MacMahon S, Maggioni A, Marchioli R, Marschner I, Mihaylova B, Moyé L, Murphy S, Nakamura H, Neil A, Newman C, Connell R, Packard C, Parish S, Pedersen T, Peto R, Pfeffer M, Poulter N, Preiss D, Reith C, Ridker P, Robertson M, Sacks F, Sattar N, Schmieder R, Serruys P, Sever P, Shaw J, Shear C, Simes J, Sleight P, Spata E, Tavazzi L, Tobert J, Tognoni G, Tonkin A, Trompet S, Varigos J, Wanner C, Wedel H, White H, Wikstrand J, Wilhelmsen L, Wilson K, Young R, Yusuf S, Zannad F. Efficacy and safety of statin therapy in older people: a meta-analysis of individual participant data from 28 randomised controlled trials. Lancet. 2019;393:407-15. https:// doi.org/10.1016/S0140-6736(18)31942-1.

13. Mancini GBJ, Baker S, Bergeron J, Fitchett D, Frohlich J, Genest J, Gupta M, Hegele RA, Ng D, Pearson GJ, Pope J, Tashakkor AY. Diagnosis, prevention, and management of statin adverse effects and intolerance: canadian consensus working group update (2016). Can J Cardiol. 2016;32:S35-65. https://doi.org/10.1016/j. cjca.2016.01.003.

14. Kopterides P, Falagas ME. Statins for sepsis: a critical and updated review. Clin Microbiol Infect. 2009;15:325-34. https://doi.org/10. 1111/j.1469-0691.2009.02750.x.

15. Björkhem-Bergman L, Bergman P, Andersson J, Lindh JD. Statin treatment and mortality in bacterial infections-a systematic review and meta-analysis. PLoS ONE. 2010;5:e10702. https:// doi.org/10.1371/journal.pone.0010702.

16. Jin J-M, Bai P, He W, Wu F, Liu X-F, Han D-M, Liu S, Yang J-K. Gender differences in patients with COVID-19: focus on severity and mortality. Front Public Heal. 2020;8:152. https:// doi.org/10.3389/fpubh.2020.00152.

17. Gebhard C, Regitz-Zagrosek V, Neuhauser HK, Morgan R, Klein SL. Impact of sex and gender on COVID-19 outcomes in Europe. Biol Sex Differ. 2020;11:29. https://doi.org/10.1186/ s13293-020-00304-9.

18. Williams $C$, Wheeler D. Criteria for ICU admission and severity of illness scoring. Surgery. 2009;27:201-6. https://doi.org/10. 1016/j.mpsur.2009.04.006.

19. Zhang X-J, Qin J-J, Cheng X, Shen L, Zhao Y-C, Yuan Y, Lei F, Chen M-M, Yang H, Bai L, Song X, Lin L, Xia M, Zhou F, Zhou J, She Z-G, Zhu L, Ma X, Xu Q, Ye P, Chen G, Liu L, Mao W, Yan Y, Xiao B, Lu Z, Peng G, Liu M, Yang J, Yang L, Zhang C, Lu H, Xia X, Wang D, Liao X, Wei X, Zhang B-H, Zhang X, Yang J, Zhao G-N, Zhang P, Liu PP, Loomba R, Ji Y-X, Xia J, Wang Y, Cai J, Guo J, Li H. In-hospital use of statins is associated with a reduced risk of mortality among individuals with COVID-19. Cell Metab. 2020;32:176-187.e4. https://doi.org/10.1016/j.cmet.2020.06.015. 
20. Kow CS, Hasan SS. Meta-analysis of effect of statins in patients with COVID-19. Am J Cardiol. 2020;134:153-5. https://doi. org/10.1016/j.amjcard.2020.08.004.

21. Onorato D, Pucci M, Carpene G, Henry BM, Sanchis-Gomar F, Lippi G. Protective effects of statins administration in European and North American patients infected with COVID-19: a meta-analysis. Semin Thromb Hemost. 2021. https://doi.org/10. 1055/s-0040-1722307.

22. Gupta A, Madhavan MV, Poterucha TJ, DeFilippis EM, Hennessey JA, Redfors B, Eckhardt C, Bikdeli B, Platt J, Nalbandian A, Elias P, Cummings MJ, Nouri SN, Lawlor M, Ranard LS, Li J, Boyle C, Givens R, Brodie D, Krumholz HM, Stone GW, Sethi SS, Burkhoff D, Uriel N, Schwartz A, Leon MB, Kirtane AJ, Wan EY, Parikh SA. Association between antecedent statin use and decreased mortality in hospitalized patients with COVID19. Res Sq. 2020. https://doi.org/10.21203/rs.3.rs-56210/v1.

23. Totura AL, Whitmore A, Agnihothram S, Schäfer A, Katze MG, Heise MT, Baric RS. Toll-like receptor 3 signaling via TRIF contributes to a protective innate immune response to severe acute respiratory syndrome coronavirus infection. MBio. 2015;6:e0638-e715. https://doi.org/10.1128/mBio.00638-15.

24. Sheahan T, Morrison TE, Funkhouser W, Uematsu S, Akira S, Baric RS, Heise MT. MyD88 is required for protection from lethal infection with a mouse-adapted SARS-CoV. PLoS Pathog. 2008;4:e1000240. https://doi.org/10.1371/journal.ppat. 1000240

25. DeDiego ML, Nieto-Torres JL, Regla-Nava JA, Jimenez-Guardeno JM, Fernandez-Delgado R, Fett C, Castano-Rodriguez C, Perlman S, Enjuanes L. Inhibition of NF-B-mediated inflammation in severe acute respiratory syndrome coronavirus-infected mice increases survival. J Virol. 2014;88:913-24. https://doi. org/10.1128/JVI.02576-13.

26. Totura AL, Baric RS. Reply to "Statins may decrease the Fatality Rate of MERS Infection. MBio. 2015;2015:6. https://doi. org/10.1128/mBio.01303-15.

27. Yuan X, Deng Y, Guo X, Shang J, Zhu D, Liu H. Atorvastatin attenuates myocardial remodeling induced by chronic intermittent hypoxia in rats: partly involvement of TLR-4/MYD88 pathway. Biochem Biophys Res Commun. 2014;446:292-7. https:// doi.org/10.1016/j.bbrc.2014.02.091.

28. Yuan S. Statins may decrease the fatality rate of middle east respiratory syndrome infection. MBio. 2015;6:e01120. https://doi. org/10.1128/mBio.01120-15.
29. Fedson DS, Opal SM, Rordam OM. Hiding in plain sight: an approach to treating patients with severe COVID-19 infection. MBio. 2020;2020:11. https://doi.org/10.1128/mBio.00398-20.

30. Shyamsundar M, McKeown STW, O'Kane CM, Craig TR, Brown V, Thickett DR, Matthay MA, Taggart CC, Backman JT, Elborn JS, McAuley DF. Simvastatin decreases lipopolysaccharideinduced pulmonary inflammation in healthy volunteers. Am J Respir Crit Care Med. 2009;179:1107-14. https://doi.org/10. 1164/rccm.200810-1584OC.

31. Chen W, Sharma R, Rizzo AN, Siegler JH, Garcia JGN, Jacobson JR. Role of claudin-5 in the attenuation of murine acute lung injury by simvastatin. Am J Respir Cell Mol Biol. 2014;50:32836. https://doi.org/10.1165/rcmb.2013-0058OC.

32. Rogers AJ, Guan J, Trtchounian A, Hunninghake GM, Kaimal R, Desai M, Kozikowski L-A, DeSouza L, Mogan S, Liu KD, Matthay MA, Steingrub J, Wheeler A, Yoon JH, Nakahira K, Choi AM, Baron RM. Association of elevated plasma interleukin-18 level with increased mortality in a clinical trial of statin treatment for acute respiratory distress syndrome*. Crit Care Med. 2019;47:1089-96. https://doi.org/10.1097/CCM.0000000000 003816.

33. Garnacho-Montero J, Barrero-García I, Gómez-Prieto MG, Martín-Loeches I. Severe community-acquired pneumonia: current management and future therapeutic alternatives. Expert Rev Anti Infect Ther. 2018;16:667-77. https://doi.org/10.1080/14787210. 2018.1512403.

34. Makris D, Manoulakas E, Komnos A, Papakrivou E, Tzovaras N, Hovas A, Zintzaras E, Zakynthinos E. Effect of pravastatin on the frequency of ventilator-associated pneumonia and on intensive care unit mortality: open-label, randomized study*. Crit Care Med. 2011;39:2440-6. https://doi.org/10.1097/CCM.0b013e3182 25742c.

35. Papazian L. Effect of statin therapy on mortality in patients with ventilator-associated pneumonia. JAMA. 2013;310:1692. https:// doi.org/10.1001/jama.2013.280031.

36. Vandermeer ML, Thomas AR, Kamimoto L, Reingold A, Gershman K, Meek J, Farley MM, Ryan P, Lynfield R, Baumbach J, Schaffner W, Bennett N, Zansky S. Association between use of statins and mortality among patients hospitalized with laboratoryconfirmed influenza virus infections: a multistate study. J Infect Dis. 2012;205:13-9. https://doi.org/10.1093/infdis/jir695. 